\title{
Assessment of Effective Organizational Communication on Organizational Silence and Organizational Citizenship Behavior
}

\author{
Mohammad Ali Manafzadeh ${ }^{*}$, Esmail Ghaderi², Mohammad Reza Moradi ${ }^{3}$, \\ Samira Taheri ${ }^{1}$ and Parya Amirhasani ${ }^{4}$ \\ ${ }^{1}$ Ph.D. Candidate in Marketing Management, Department of Management, Sanandaj Branch, \\ Islamic Azad University, Tehran, Iran; ma.manafzadeh@yahoo.com \\ 2Ph.D. Candidate in Marketing Management, Department of Management, \\ Sanandaj Branch, Islamic Azad University, Isfahan, Iran \\ ${ }^{3}$ Ph.D. Candidate in Marketing Management, Department of Management, \\ Sanandaj Branch, Islamic Azad University, Kermanshah, Iran \\ ${ }^{4}$ BA Clinical Psychology, University of Kurdistan, Sanandaj, Iran
}

\begin{abstract}
This study aimed to determine effective organizational communication with Organizational Silence and Organizational Citizenship Behavior is done. This research is a quantitative and descriptive survey method. The study population consisted of all employees in the country's Export Development Bank whose number is 1,200, a sample according to the sample of 291 was achieved using twostage cluster online questionnaire was distributed among the population under study and the sample was calculated according to the formula Cochran 291, the cluster using two-step online questionnaire was distributed among the population under study. The tool data is measured using standard questionnaires and effective organizational communications questionnaire (25 questions), organizational silence ( 25 questions) and organizational citizenship behavior ( 25 questions) which is then distributed between the staff number of 284 questionnaire were collected. Data analysis was performed using structural equation and software Lisrel. Analysis shows the overall indices measure the overall model is perfectly acceptable situation. The results show an inverse relationship between effective organizational communication and organizational silence (0.86-) there is a significant and also an inverse relationship between organizational silence and organizational citizenship behavior (0.19-) there is a significant, and finally a positive relationship between organizational communication effectiveness and organizational citizenship behavior (0.16) significantly there.
\end{abstract}

Keywords: Effective Communication, Export Development Bank of Iran, Organizational Citizenship Behavior, Organizational Silence

\section{Introduction}

Despite the increasing use of information technology, there is still a gap in the organization's performance and performance. It is now strongly believed that the performance of the organization depends to a large extent on efforts beyond the requirements of the staff (Ibrahimpour et al., 2012). The very changing and changing conditions governing organizations and their entry into the knowledge-based economy, increasing competition and the need for the effectiveness of organizations today reveal the need for a valuable generation of employees as organizational troops $s^{17}$. Today, actions and behaviors are more than expected to be outlined in the job description and a new wave of existing knowledge has created organizational performance benefits ${ }^{14}$. Over the past 25 years, researchers have attempted to identify, through multiple researches, those employee behaviors that make their mental and social status more effective and effective ${ }^{13}$. These behaviors include helping others, tolerance of incompatibility, participation in corporate affairs, supporting the organization or becoming volunteers

${ }^{*}$ Author for correspondence 
for responsibilities beyond the duty and can be responded promptly (in response to a request for help) or actively (offer assistance to a partner $)^{4}$. Such behaviors are conceptualized in a variety of ways and with different titles, but are often discussed as organizational citizenship behaviors; behaviors that emphasize the interests of the group and organization on individual interests ${ }^{15}$. Organizational citizenship behavior includes behaviors for the formation of a job and requires that these behaviors contribute to the overall success of the organization. Since the 1970s, organizational citizenship behavior has been studied and there are many theoretical foundations about $\mathrm{it}^{20}$. Based on organizational theories, organizational citizenship behavior is clearly contributing to the organization's competitiveness and performance, as well as the willingness and willingness to behave as a result of the growing global competition is of particular importance. Today, these behaviors are considered to be integral to performance management and have entered into different aspects of the organization. Considering that increasing the effectiveness and consequently, excellence among competitors is always one of the issues and concerns of managers, recognizing organizational citizenship behavior and its areas of deployment can be considered as an effective and useful step in this direction ${ }^{11}$. The key elements of organizational citizenship behavior are: (1) Behavioral, beyond formal formalization by organizations, (2) is completely optional, (3) not directly attributed to the official organization structure of the organization, and (4) is essential for the success and performance of the organization ${ }^{12}$.

Today, in many organizations, employees are refusing to give their opinions and ideas about organizational issues and there is a climate in organizations that often make employees feel that their opinions are not worthy of and that employees are free to express ideas ${ }^{7}$. One of the hallmarks of organizational disregard is organizational silence. An unimportant person does not care about compliance with the organization's rules and regulations and the proper use of the resources and facilities of the organization ${ }^{16}$. Organizational silence considers an ineffective organizational process that results in waste of costs and efforts and can involve various forms such as collective silence in meetings, low participation rates, and lack of talk about the organization (Dan et al., 2009) . Organizational silence by limiting employees' comments reduces the effectiveness of organizational decision making and changing processes and this is the subject that many organizations are afraid of (Gallavandi and Moradi, 2015). Also, this behavioral phenomenon is effective in preventing negative feedback from obstructing organizational transformation. Therefore, the organization loses the ability to check and correct errors. Therefore, attention to this common problem in organizations is very important. In general, two categories of beliefs are related to silence of individuals. One is that talking about the organization's issues is futile. Moreover, talking about organizational issues is detrimental to one's person ${ }^{3}$. Indeed, hierarchical communications often encourage silence in order to justify that the manager has expertise and can understand the issues. In addition, some individuals are personally in such a way that these types of structures and relationships reinforce their silence (Benowitz, 2001).

Communication in organizational studies is an important factor in organizational success and is central to organizational theories ${ }^{19}$. Since communication is a process in which planning, organizing, guiding, managing and controlling tasks is done, it can be said that maintaining healthy and effective communication in organizations and institutions helps to reduce or eliminate the tensions in the course of doing these. Relationships are the cause of organizational renewal and its continuity and dynamism. Effective communication is one of the key factors in the success of managers and not only provides the basis for the development of the organization, but the continuity of life in any organization depends ${ }{ }^{1}$. Communication focuses on the performance of managers. Most managers spend more than $75 \%$ of their time on communication ${ }^{5}$. Communication not only ensures coherence and coordination among units, but also extracts valuable information from the outside environment and transfers units, groups and individuals. Effective communication requires effective management and is enhanced by the growth and development of the organization. As a result, it is necessary to make adjustments in communication systems in terms of the shape, size, function, location and services that the organization offers ${ }^{10}$.

Organizational communication is a kind of exchange of information that provides the basis for perception and feeling between two or more people, with a group in the company or organization, and causes organizational networks to form part of organizational ${ }^{6}$. Relationships between individuals and groups are essential if organizations are to be of high efficiency and to cope with the increasing turbulence of the $21^{\text {st }}$ century business market. None of the manager's duties is as vital as communication. Communication is like a link that relates actions and activities of individuals and organizations to desired goals. Communication is a way that employees share their emotions, thoughts, desires and needs (Benowitz, 2001). Recent research has shown the key role of organizational communication in the effectiveness of organizations and attainment of their goals. Communication is the key to the success of the organization. If the employee is silent, he actually suffers from inappropriate communication, resulting in gross damage to the organiza$t^{2}{ }^{2}$. Experience has shown that the freedom to communicate with supervisors and colleagues leads to sharing information, ideas, opinions and suggestions, which ultimately leads to increased participation and a sense of unity and belonging to the organization. The unwillingness to share information, 
talk and provide feedback negatively affects employees' trust, morale and motivation ${ }^{18}$.

As we know, employee behavior at work has important implications for overall organizational effectiveness and effectiveness. Organizational behavior is related to the organization's overall efficiency and organizational citizenship behavior positively contributes to the overall organization's efficiency. This way, the path to achieving the objectives of the organization is facilitated. In addition to the necessity of these behaviors in the current changing world, voluntary cooperation is a key factor in the effective implementation of strategic decisions. Implementing the goals of a strategic decision requires the creativity and simultaneous action of the staff and both require a spirit of voluntary cooperation, so one of the main challenges of management is how to engage in this collaboration. In this research, the relationship between effective organizational communication and organizational silence and organizational citizenship behavior has been investigated. For this purpose, correlation, standard values, mean, and structural equation modeling and path analysis have been calculated to determine the effects of research variables among the Export Development Bank staff.

\section{Conceptual Model of Research}

Despite its great interest in the study of organizational citizenship behavior, its dimensions have not yet been fully understood. A review of the literature of this concept has potentially identified about thirty different behaviors ${ }^{15}$; however, due to the large overlap between these behaviors, they can be categorized in five general categories, altruism, politeness, Chivalry, conscience and civic virtue ${ }^{20}$. In this research, following the study of effective organizational communication models, the Robins model (2005) was the basis for study, because the components of effective communication in this model are more consistent with the research community, which has six indicators: using multiple communication channels, simplifying, listening Active activation, emotional control, unofficial communication networks, and use of feedback. Dyne et al., (2003) categorized silence into three types of submissive silence, defensive silence and altruistic silence, which is the basis for studying this research.

\section{Methodology}

The purpose of this study is to apply a study because according to the conceptual model of the research and according to the extracted indicators of literature, the evaluation of effective organizational relations on organizational silence and organizational citizenship behavior in the Export Development Bank of the country has been studied and the results Research can help your bank or other organizations. The purpose of applied research is the development of applied knowledge in a particular context. On the other hand, in terms of the relationship between variables, this research is a descriptive-correlational study. The statistical population of this study is the total of 1200 employees of the Export Development Bank in the country and the sample was 291 according to the Cochran formula. Using a two-stage cluster sampling method, the population of the study was Intranet questionnaire. The questionnaires were distributed and repeatedly followed by deletion of incomplete questionnaires. Finally, 284 questionnaires were used as the basis for the final analysis. The main tool for collecting data in this study was a questionnaire which was prepared using

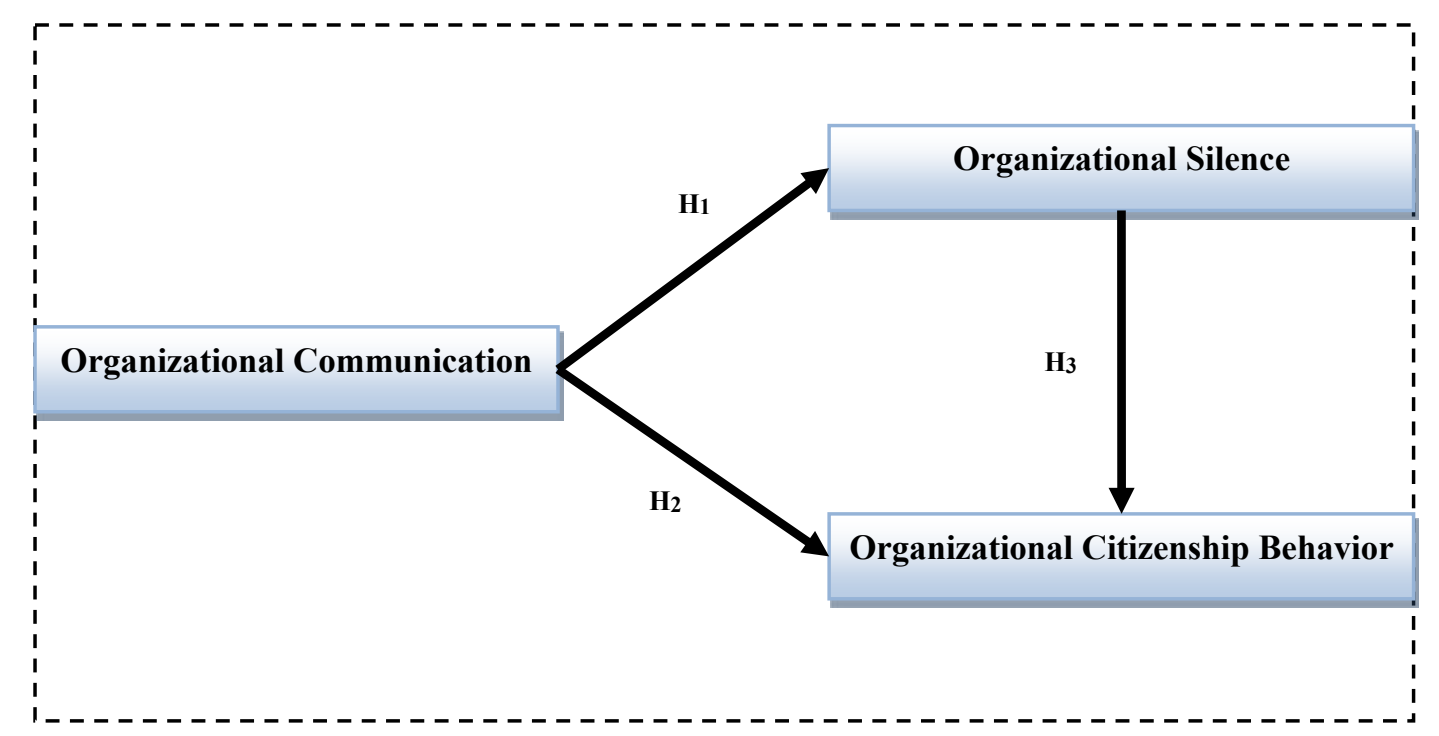

Figure 1. Conceptual model of research. 
an adapted questionnaire from Robbins (2005) for Effective Organizational Communication (EOC), Wacola and Borados (2005) for Organizational Silence (OS) and Baldrem (2014) for Organizational Citizenship Behavior (OCB).

\section{Findings}

After describing the variables and the responses obtained from the statistical society in this section, the hypotheses are considered, and the statistical test used in the research has been studied. In other words, in this section, the analysis of the obtained findings is done so that the assumptions can be verified statistically. To assess the effective organizational communication, organizational silence and organizational citizenship behavior structural equation modeling with LISREL software is used. The purpose of the direct and indirect effects of the discovery of hidden variables is exogenous to endogenous latent variables.

Chart 3 shows the modified models for coefficients significance ( $\mathrm{t}$-value). This model actually tests all measurement equations (loading factor) and structural equations using $t$ statistic. Based on this model, path coefficient and loading factor is significant at $95 \%$ level if $\mathrm{t}$ statistic value is beyond $-1.96-+1.96$.
All the main research hypotheses are confirmed in this study. For all variables path coefficient $T$ is more than $1 / 96$, thus confirming the hypothesis is dumped.

\section{Conclusion}

Queuing staff in service organizations is an important source of differentiation and competitive advantage. The quality of service, customer satisfaction and brand of organizations are affected by the actions and behavior of the first line employees. As banks under the supervision of the Central Bank, banks are required to comply with all the laws and regulations communicated by the Central Bank. This indicates that the banks are not in a position to determine the interest rates on deposits and facilities; in such circumstances, competition in the financial and monetary spheres. Hard to lose their true meaning and banks will have to use other tools to maintain and enhance their competitive advantage. Effective communication is one of the effective factors in reducing organizational silence. Organizational silence has an irrevocable effect on reducing employee participation. Effective and correct communication in the organization is always one of the important components of management success. It has been proven to be that if the

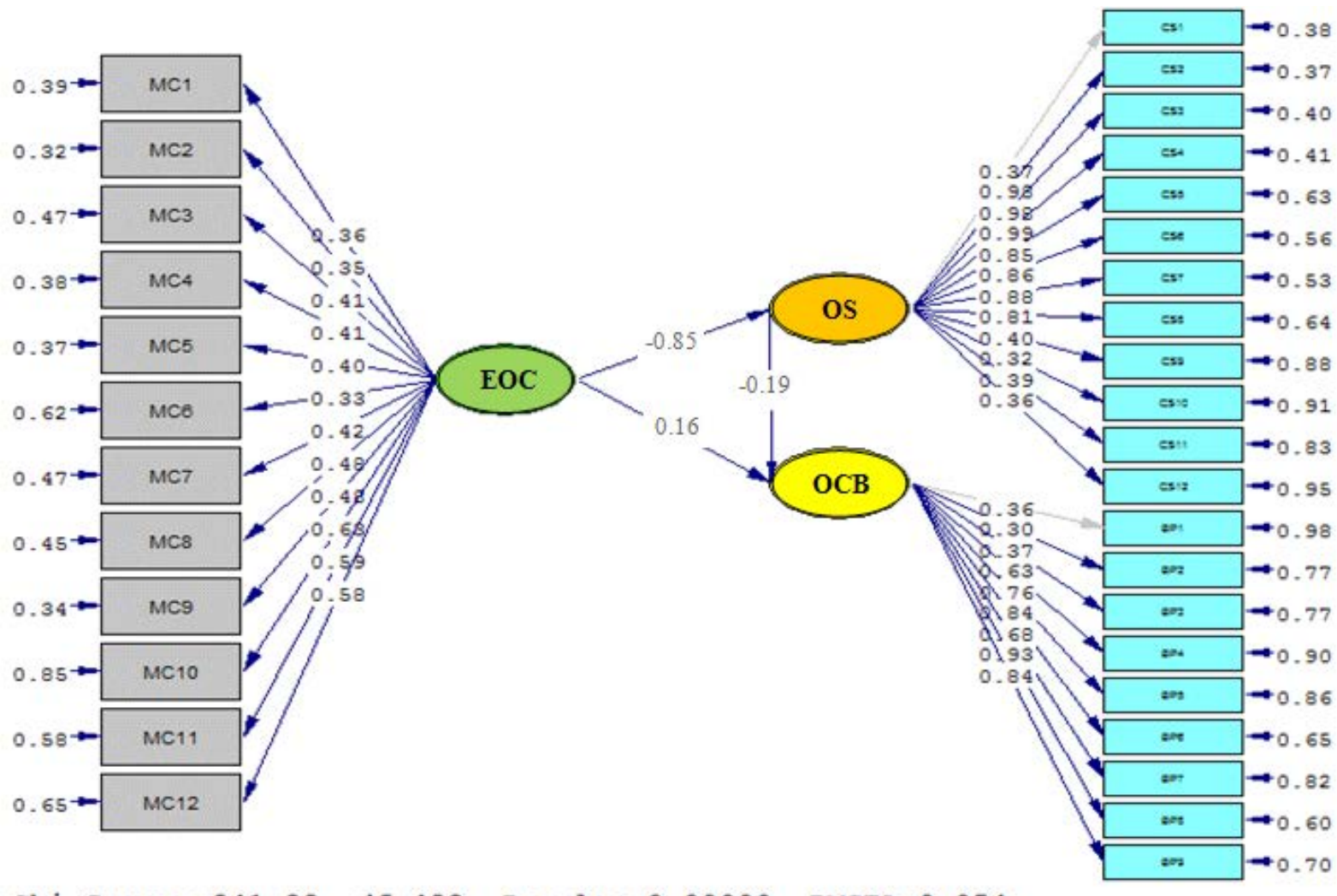

Chi-square $=941.99, d f=492, \quad p-v a l u e=0.00000$, RMSEA $=0.054$

Figure 2. Modified model for standard coefficient estimation. 


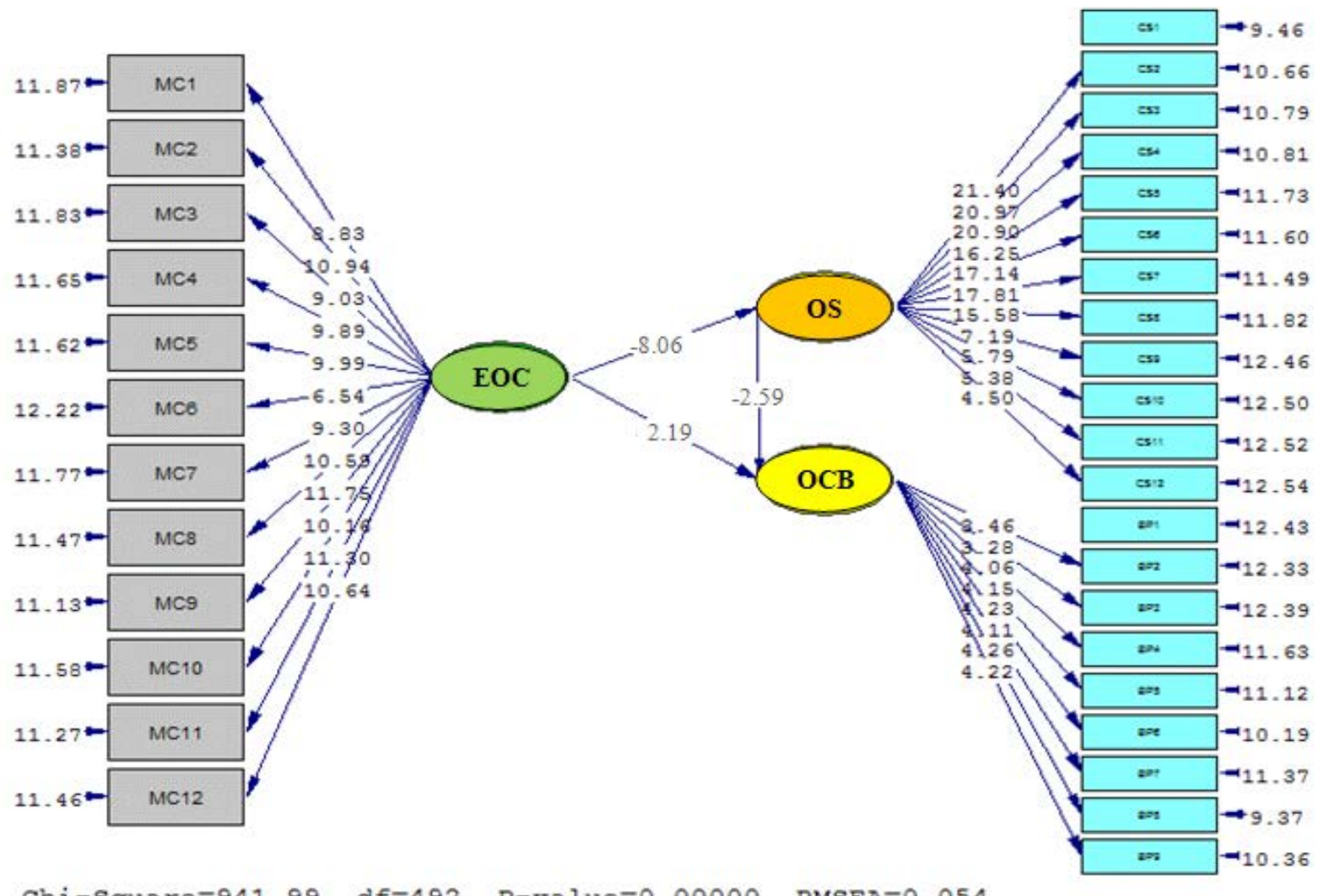

Chi-square $=941.99, d f=492, \quad P-v a l u e=0.00000$, RMSEA $=0.054$

Figure 3. Modified model for significance (t-value).

Table 1. The results of the study hypotheses

\begin{tabular}{|c|c|c|c|}
\hline Direction & Path coefficient & $\mathrm{T}$ & Result \\
\hline H1: Effective Organizational Communication à Organizational Silence & -0.85 & -8.06 & confirmation \\
\hline H2: Effective Organizational Communication à Organizational Citizenship Behavior & 0.16 & 2.19 & confirmation \\
\hline H3: Organizational Silence à Organizational Citizenship Behavior & -0.19 & -2.59 & confirmation \\
\hline
\end{tabular}

correct communication does not exist in the organization, the circulation of affairs becomes disturbed.

\subsection{The First Hypothesis Test}

There is an inverse and significant relationship between the effective organizational communications with the organizational silence of the export development bank staff.

The meaningful number of the path between the variable of organizational communication with organizational silence according to (2), (3) and table (1) is equal to (-8.06), which is greater than (1.96), so the relationship between these two variables is confirmed at a $99 \%$ confidence level. The coefficient of the path between these two variables is equal to the value $(-0.85)$ and this indicates that for a unit of change in the effective organizational communication variable, the organizational silence variable (0.85) will change. The findings of this hypothesis are based on Danaeifard and Panahi (2010) that, as little communication opportunities exist in the organization, employees often silence, Vakola and Borados (2005) state that there is a negative relationship between communication opportunities and employee silence behavior. Zahir and Erdogan (2011) suggest that appropriate and open leadership behavior leads to a decrease in silence and Danaeifard and Panahi et al., (2012) that there is a negative correlation between communication opportunities and organizational commitment of employees. Therefore, the main hypothesis of the first research is confirmed with $99 \%$ confidence and effective organizational communication with organizational silence in the branches of the Export Development Bank of the country has a significant and significant relationship. 


\subsection{The Second Hypothesis}

There is a positive and significant relationship between effective organizational communication and organizational citizenship behavior of Export Development Bank staff.

The significant number of paths between the variable of effective organizational communication with organizational citizenship behavior according to Figures (2), (3) and Table (1) is equal to $(2.19)$ which is greater than $(1.96 \pm 1)$, so the relationship between These two variables are confirmed at a confidence level of $99 \%$. The path coefficient between these two variables is estimated to be equal to $(0.16)$ and this figure shows that the increment in the effective organizational communication variable increases the organizational citizenship behavior variable (0.16). Organizational communication is the most important tool that can be used to deal with different situations in the organization. Therefore, citizenship behavior helps to understand the components of organizational communication quickly and correctly ${ }^{16}$. Communication is required not only to create appropriate networks between managers and employees, but also for implicit assistance to the overall performance and performance of the organization. Based on the findings, effective organizational communication should be considered as an important issue for enhancing organizational citizenship behavior ${ }^{20}$. Therefore, the third main hypothesis of the research is confirmed with $99 \%$ confidence and effective organizational communication with organizational citizenship behavior in the branches of the Export Development Bank of Iran has a positive and direct relationship.

\subsection{The Third Hypothesis}

There is an inverse and significant relationship between organizational silence and organizational citizenship behavior of the Export Development Bank staff.

The significant number of paths between the organizational silence variable with organizational citizenship behavior according to (2), (3) and table (1) is equal to (-2.59), which is greater than $(1.96 \pm 1)$, so the relationship between these two variables are confirmed at a confidence level of $99 \%$. The path coefficient between these two variables is estimated to be equal to the value $(-0.19)$. This indicates that for a unit of change in the organizational silence variable, the organizational citizenship behavior variable (0.19) will change. Studies show that there is always a negative relationship between organizational silence and organizational citizenship behavior (Sabouri et al., 2013). Sinar et al., (2013) proved this in their study. The reduction of organizational silence increases organizational citizenship behavior. Therefore, it can be said that if employees have the necessary support in expressing and expressing their thoughts and opinions about tasks, organization and management, their level of organizational citizenship behavior will increase and they will have the feeling that they will help as a member of the organizational family. Have an active participation. Considering that one of the indicators of organizational silence reduction is the creation of a communication atmosphere between managers and employees, thus, managers can create organizational environments with a positive environment, thereby reducing organizational silence and, consequently, increasing organizational noise. Therefore, the second main hypothesis of the research is confirmed with $99 \%$ confidence and organizational silence with organizational citizenship behavior in the branches of the Export Development Bank of the country has a significant and significant relationship.

This study, like other studies and studies, has been confronted with limitations. One may mention that some employees may have been conservative in answering some of the questions due to the fear that the questionnaires may have been communicated by the head of the organization, which may well be correct. Responses and validity of the results.

\section{References}

1. Alipour FH. The relationship between organizational climate and communication skills of managers of the Iranian physical education organization. Procedia-Social and Behavioral Sciences. 2011; 30: 421-428.

2. Bagheri G, Zarei R and Nik Aeen M. Organizational silence (basic concepts and its development factors). Ideal Type of Management. 2012; 1(1): 47-58.

3. Bogosian R. Silence is not always consent: Employee silence as a barrier to knowledge transfer. The 2013 Organizational Learning, Knowledge and Capabilities Conference (OLKC); 2013.

4. Bolino MC, Harvey J and Bachrach DG. A self-regulation approach to understanding citizenship behavior in organizations. Organizational Behavior and Human Decision Processes. 2012; 119: 126-139.

5. Carriere J and Bourque C. The effects of organizational communication on job satisfaction and organizational commitment in a land ambulance service and the mediating role of communication satisfaction. Telfer School of Management, Career Development International. 2009; 14(1): 29-49.

6. Dessler G and Phillips J. Managing now. Boston: New York: Houghton Mifflin Company. 2008

7. Dimitris B and Maria V. Organizational silence: A new challenge for human resource management. Athens University of Economics and Business. 2007. 1-19.

8. Ebrahim PH, Hasan Z, Mohammad, NV. Organizational citizenship behavior and tourist. Tourism Management Studies. 2012; 7(18).

9. Ghalavandi $\mathrm{H}$ and Zahra M. Relationship analysis of organizational moral climate, organizational identity and organizational silence. Journal of Ethics in Science and Technology. 2015; 10(3). 
10. Kondalkar VG. Organizational behavior, New Delhi: New Age International (P) Ltd., Publishers. 2007.

11. Markoczy L and Xin K. The virtues of omission organizational citizenship behavior. University of California. 2015. 27-28.

12. Netemeyer RG, Bowles JS, Mackee DO and McMurrian R. An investigation into the antecedents of organizational citizenship behaviors in personal selling context. Journal of Marketing. 1997; 61: 85--95.

13. Organ DW, Podsakoff PM and MacKenzie SB. Organizational citizenship behavior: its nature, antecedents, and consequences. Thousand Oaks: CA:Sage Publications. 2006.

14. Peng JC and Chiu SF. An integrative model linking feedback environment and OCB. The Journal of Social Psychology. 2010; 150(6): 582-607.

15. Podsakoff PM, MacKenzie SB, Paine J.B. and Bachrach, D.G. Organizational citizenship behaviors: A critical review of the theoretical and empirical literature and suggestions for future research. Journal of Management. 2000; 26: 513-563.
16. Sadatyar FS and Elaheh SZ. A study of the global studies on the consequences of the genesis and the prevalence of the inner organization's silence and silence among police officers. Quarterly Journal of Supervision and Inspection. 2015; 9(3).

17. Taghizzadeh $\mathrm{H}$ and Abdol-Hussein S. Applying interpretive structural modeling in grading organizational citizenship behavior indices in foreign language institutes: A case study. Quarterly Journal of New Approach in Educational Management. 2014; $5(3)$.

18. Vakola M and Bouradas D. Antecedents and consequences of organizational silence: An empirical investigation". Employee Relations. 2005; 27(5): 441-458.

19. Worley A. Personnel Management. $8^{\text {th }}$ Ed. America: John Willey and Sons, Inc. 2006.

20. Yildrim $\mathrm{O}$. The impact of organizational communication on organizational citizenship behavior: research findings. Procedia - Social and Behavioral Sciences. 2014; 150(2014): 1095-1100. 